\title{
Results of selective treatment of spina bifida cystica
}

\author{
JOHN LORBER AND STEPHEN A W SALFIELD \\ Department of Paediatrics, University of Sheffield
}

SUMMARY The results of selective treatment in 120 infants with open spina bifida, admitted between May 1971 and December 1976, were prospectively studied. Seventy-one infants had adverse criteria at birth and were not treated. They all died, more than $90 \%$ of them within 6 months of birth. Seven had meningocele. All were treated and survived without handicap. Forty-two infants with myelomeningocele were actively treated. Thirty-six survive at follow-up after 3 to 9 years. The quality of survival is much better than when selection was not used but 8 children have moderate or severe handicaps. The parents were fully informed and consulted at every decision-making step; they fully supported the principle of selection and the action taken on behalf of their own child.

The severity of handicap suffered by children treated unselectively for spina bifida cystica varies from no handicap in a fortunate few, to extensive, crippling, multisystem handicaps in many children. ${ }^{12}$ One-third of the survivors are mentally retarded. There was a high mortality rate in the initially severely affected infants, which continued well beyond infancy. Studies in the UK and elsewhere show that most severely affected babies who are not operated on in the newborn period die in the first few months. ${ }^{3-9}$

Patients who survive with severe handicaps and who require constant medical and surgical care for as long as they live have immense social, psychological, and financial difficulties, and so too do their families. ${ }^{10-12}$ The prospects for open employment, marriage, or anything approaching a normal life are poor, and the cost to the community is immense.

In two large retrospective surveys ${ }^{12}$ of unselectively treated children, a set of adverse criteria was identified which, if present at birth, was associated with an unfavourable prognosis: (1) gross paralysis of the legs (paralysis below 3rd lumbar segmental level, with at most hip flexors, adductors, and quadriceps being active); (2) a thoracolumbar or thoracolumbosacral lesion; (3) clinically evident kyphosis or scoliosis; (4) grossly enlarged head with occipitofrontal head circumference at least $2 \mathrm{~cm}$ above the 90th centile; (5) birth injury; (6) other gross congenital abnormalities.

Since May 1971, a policy of selective treatment of newborn infants with spina bifida cystica has been used in all infants referred to one of us (JL). The early results of this policy ${ }^{3}$ showed that 25 untreated infants had died before they reached age 9 months.
One of the 12 treated infants died and the others were at most moderately handicapped.

In recent years these adverse criteria have been accepted as a basis for selection in the UK and in many other countries. The present study, which includes the earlier series, was therefore undertaken too review our results using these adverse criteria, 9 years after starting a policy of selection.

\section{Patients and methods}

Between May 1971 and December 1976, 120 newborn infants with open spina bifida cystica were referred to one of us (JL). Seven of these had meningocele and 113 had myelomeningocele. Most patients were referred from within the Trent region.

After full assessment of the infant the father, and if possible the mother too, was interviewed. If the mother was not present the father was interviewed together with members of his wife's family if possible, and the father was asked to discuss the matter with his wife, and return with a final decision. Subsequently, all the mothers were personally interviewed.

Almost all the assessments and interviews were conducted by one of us (JL) at any time of the day or night, or occasionally it was the duty of the senior assistant. A member of the junior medical staff together with a member of the nursing staff who would be looking after the baby were always present at the interview.

The infant's condition was discussed and the choice between active and non-active management was simply and repeatedly explained. A prognosis was given of the minimum handicap the child would 
have if total treatment were to be given, or the likelihood or approximate length of survival if the child were not treated. Frequently, in mildly affected babies, strong reassurance was given because the parents tended to assume the worst when told their baby had spina bifida.

At the end of the interview, which could last up to 2 hours, a recommendation for or against treatment was made. If the advice was against active treatment the parents were offered a second opinion. No parents wanted a second opinion, and none wanted treatment against our advice.

In 2 cases near the 'borderline', the parents did not agree to the recommended active treatment and their decision was accepted. Several parents of less severely affected patients were initially hesitant but agreed to treatment when the fairly good prognosis and the probability of survival, even in the absence of treatment, were explained.

Infants who were not treated actively were either looked after in the medical ward or were transferred back to the referring hospital. No further investigations were performed. Normal nursing care with feeds on demand were given, but these infants were not tube fed or treated with antibiotics. Chloral hydrate was used to treat irritability or discomfort. It was the parents' universal wish that everything should be done to prevent suffering. A few parents decided to take their untreated infants home.

If treatment was decided on, the infant was immediately referred to our Paediatric Surgical Unit for active treatment.

Hydrocephalus, if present in infants being actively treated, was assessed by air ventriculography and intraventricular pressure measurements soon after the closure of the back. Computerised tomography (CT) was not available during this period. The initial treatment of hydrocephalus was generally with isosorbide 1314 given orally or by nasogastric tube. Only if there was evidence that the hydrocephalus could not be controlled by isosorbide, or if the hydrocephalus was severe at birth, was shunt surgery embarked upon.

All the treated patients were followed up in a combined clinic where they were seen by paediatrician, paediatric surgeon and orthopaedic surgeon, with full supporting staff. Initially the children were seen frequently; after their second birthday they were seen at least once a year. The children who attend special schools were often accompanied by their nurses and physiotherapists as well as their parents. Problem-orientated records have been kept since birth on every patient for prospective study.

Four patients have been discharged from the clinic as each was normal and there were no foreseeable problems. Their parents were contacted by letter in 1979 and no new problems have arisen. No patient has been lost to follow-up.

The degree of handicap was classified as slight, moderate, or severe at the last assessment (near the child's birthday in 1979/80, Table 1). These lists of possible handicaps are not complete, but are used as a guide to the overall degree of handicap.

\section{Results}

Treated infants $(n=49)$. Seven infants each had a simple meningocele. They recovered without sequelae and none had hydrocephalus. Their treatment presented neither clinical nor ethical problems.

All the subsequent analysis relates to the 42 with myelomeningocele.

Three had thoracolumbar lesions. Their treatment was advised, against the protocol, for various reasons (see Severely handicapped children). All survive with severe sequelae and one is mentally retarded.

The remaining 39 infants had either small thoracic, low lumbar, lumbosacral, or sacral lesions (Table 2).

The lesions were closed on the first day in $\mathbf{3 8}$ and were closed later in 3 patients. In one infant the lesion was too broad to close and it was allowed to

\section{Table 1 Classification of degree of handicap}

Slight handicap (at least one of the following)

Below knee weakness, slight enough to allow locomotion without aids. Urinary incontinence with a normal upper urinary tract. Hydrocephalus, successfully treated by a shunt*

Moderate handicap (at least one of the following)

Moderate weakness of the legs, allowing walking with, at most, below knee calipers, and sticks. Only occasional use of a wheelchair. Urinary diversion with normal upper urinary tract. Faecal incontinence with 'moderate' social control. 'Moderate' mental retardation with IQ 60-75. Partial visual defects. Well-controlled epilepsy

Severe handicap $\dagger$ (at least one of the following)

Gross paraplegia. Locomotion possible only with extensive bracing. A wheelchair frequently used. Urinary incontinence with permanently damaged upper urinary tract. Frequent and embarrassing faecal incontinence. Severe mental retardation with IQ less than 60. Gross deformities such as gross kyphoscoliosis. Blindness. Severe, poorly controlled epilepsy

*Hydrocephalus arrested spontaneously or after treatment with isosorbide is not here considered to constitute a handicap.

IIn practice all the severely handicapped children had more than one of these factors.

Table 2 Site of lesion in 42 treated cases of myelomeningocele

\begin{tabular}{lr}
\hline Thoracic & 5 \\
Lumbar & 3 \\
Lumbosacral & 22 \\
Sacral & 9 \\
Thoracolumbar* & 3 \\
\hline
\end{tabular}

*All three survive with severe sequelae and one is mentally retarded. 
epithelialise spontaneously. He was given all other necessary surgical and medical treatment and survives.

Thirty-six survive and each was reviewed between ages 3 and 9 years.

\section{Deaths}

Six treated children died. Three died of ventriculitss in the newborn period. Two of them had hydrocephalus but this was not treated because they died early.

An exceptionally extensive Arnold-Chiari malformation was found at necropsy in an infant with hydrocephalus who had a fatal respiratory arrest on the second day of life.

The fifth, a baby with a small sacral lesion and apparently good power in his legs, was remarkably immobile. The parents were fearful, but were persuaded to agree to treatment. The parents' instinct was right however, as the baby never moved his legs after surgery and became severely retarded with a normal-sized head. He developed Escherichia coli meningitis at age 4 months; the parents refused further specific treatment and the infant died.

The sixth child, who had hydrocephalus, was of normal intelligence with normal bladder and renal function, and nearly normal legs. He died of a blocked shunt with cerebellar coning, resulting from a lumbar puncture done at another hospital. Lumbar puncture in a child with a shunt and suspected raised intracranial pressure is dangerous and is contraindicated.

\section{Survivors $(n=36)$ (Table 3)}

Without handicap $(n=10)$. Ten now have no handicap although 6 of them have hydrocephalus which has been managed without a shunt.

Slightly handicapped children $(n=8)$. In 3 children the main handicap is the presence of a shunt. One of them, who had prolonged ventriculitis after closure of her sacral lesion, is now a normal 6-year old. Despite intensive antibiotic treatment, she did not recover from her ventriculitis until continuous ventricular drainage was established. Another had closure of her spinal lesion delayed until age 3 months. She had a shunt inserted before closure of

Table 3 Degree of handicap among the 36 survivors

\begin{tabular}{lllll}
\hline $\begin{array}{l}\text { Age }(\text { years }) \\
\text { at } 1979 \text { or } 1980 \\
\text { review }\end{array}$ & Handicap & & & \\
\cline { 2 - 5 } & None & Slight & Moderate & Severe \\
\hline $6-9(\mathrm{n}=15)$ & 5 & 2 & 3 & 5 \\
$3-5(\mathrm{n}=21)$ & 5 & 6 & 5 & 5 \\
\hline
\end{tabular}

the back, not primarily for her hydrocephalus which was well controlled by isosorbide, but to facilitate the closure of the spinal lesion and prevent breakdown of the wound.

One child has multiple thoracic hemivertebrae and Sprengel's deformity, with a slight scoliosis, and a slight limp. His hydrocephalus was treated with isosorbide and he has no shunt. A recent $\mathrm{CT}$ scan shows gross hydrocephalus. He has normal intelligence and a head circumference $3 \mathrm{~cm}$ above the 97th centile. This causes him no handicap or social inconvenience.

Three children have below knee weakness allowing walking without aids. Two are incontinent with a normal upper urinary tract.

Moderately handicapped children $(n=8)$. All have moderate weakness of the legs, allowing walking with, at most, below knee calipers and sticks. Three have moderate talipes. Four are incontinent with a normal upper urinary tract.

Seven have hydrocephalus, but only 4 have shunts. All are of normal intelligence, but 2 are subject to fits.

Severely handicapped children $(n=10)$ (Table 4). Three had thoracolumbar lesions as their only adverse criteria, but were treated despite this. In one the lesion was fairly small and his legs were nearly normal at birth. He was expected to survive even if he were not operated on. Unfortunately, this infant developed spastic quadriplegia despite shunt treatment of his hydrocephalus. He also has bilateral hip dislocation, a spastic bladder, and faecal incontinence.

The second had good muscle power at birth but

Table 4 Clinical details in 10 severely handicapped children

With adverse criteria at birth (thoracolumbar lesions)

(1) Good legs at birth. Spastic quadriplegia within months. Hydrocephalus with shunt. Incontinence of urine and faeces. Dislocated hips

(2) Apparently good legs at birth. Paraplegic by 18 months. Gross hydronephrosis. Incontinence. Hemivertebrae. Gross kyphoscoliosis. Hydrocephalus treated with isosorbide

(3) Paraplegia. Absent right kidney. Gross left hydronephrosis. Gross hydrocephalus with shunt. Mental retardation. Incontinence

Without adverse criteria at birth

(4) Paraplegia. Incontinence. Hydrocephalus with shunt

(5) Paraplegia. Hydrocephalus with shunt. Incontinence. Upper urinary tract damage

(6) Severe mental retardation. Blindness after delayed recognition of shunt blockage (elsewhere). Incontinence

(7) Microcephaly. Mental retardation. Incontinence

(8) Microcephaly. Mental retardation. Paraplegia. Incontinence

(9) Lipoma of cauda equina. Severe scoliosis. Progressive neurological deterioration in legs

(10) Paralysis. Incontinence 
gradually lessening spontaneous movement in her legs until she became paraplegic by age 18 months. She has gross hydronephrosis and is incontinent of urine. She has hemivertebrae and developed kyphoscoliosis by 2 years. Her hydrocephalus was successfully treated with isosorbide and she is of normal intelligence.

The third had extensively paralysed legs at birth and was treated because of over-optimism on the part of those assessing her. She had no right kidney. Later she developed gross left-sided hydronephrosis with frequent urinary infections. She had gross hydrocephalus. Further treatment was refused by the parents and she returned to the referring hospital. She survived, but by the time she returned to us at age 2 years she had a huge head with a circumference of $62.5 \mathrm{~cm}$. A shunt was inserted but she is retarded with an IQ of 65 , and is severely handicapped.

Seven severely handicapped children had no adverse criteria at birth. Of the 3 with shunts, 2 have gross paralysis, 1 with upper urinary tract damage, but both are of normal intelligence. The third is blind and retarded after shunt blockage which was not recognised in time. By this time he was no longer our patient.

Four severely handicapped children who had no adverse criteria at birth do not have shunts. Two are microcephalic and severely mentally retarded, but the other handicaps in one of them are only moderate. The third, who had one paralysed and one normal leg at birth, had a lipoma of the cauda equina as well as a lumbosacral myelomeningocele and a thoracic meningocele. She later developed a severe scoliosis and moderate spasticity in the previously normal leg. Lipoma of the cauda equina is well known to produce progressive neurological damage $^{15} 16$ but is not associated with mortality, even if left untreated. The fourth with a lumbosacral myelomeningocele had nearly normal legs at birth but his condition gradually deteriorated and he became extensively paralysed, as did 3 children who had shunt treatment (see above).

Hydrocephalus and its treatment (Table 5). Hydrocephalus was confirmed in 29 survivors and in a shunt-treated child who died.

Table 5 Treatment of hydrocephalus in 30 infants

\begin{tabular}{lllll}
\hline $\begin{array}{l}\text { Degree of } \\
\text { hydrocephalus }\end{array}$ & $\begin{array}{l}\text { Not } \\
\text { treated }\end{array}$ & $\begin{array}{l}\text { Isosorbide } \\
\text { only }\end{array}$ & $\begin{array}{l}\text { Isosorbide } \\
\text { then shunt }\end{array}$ & $\begin{array}{l}\text { Shunt } \\
\text { only }\end{array}$ \\
\hline Slight $(\mathrm{n}=7)$ & 2 & 4 & 1 & - \\
Moderate $(\mathrm{n}=16)$ & 3 & 7 & $6^{*}$ & - \\
Severe $(\mathrm{n}=7)$ & - & 1 & 3 & 3 \\
\hline
\end{tabular}

*One died of shunt complications (see text).
The severity of the hydrocephalus was graded mild $(n=7)$, moderate $(n=16)$, or severe $(n=7)$, according to the amount of cerebral mantle found at pneumoventriculography. ${ }^{17}$

No active treatment was given to those 5 whose hydrocephalus was not severe on ventriculography and whose head grew at a normal or slightly increased rate. One of these had mild hydrocephalus shown by ventriculography. However, her head circumference increased gradually from below the 3 rd centile at birth to $1 \mathrm{~cm}$ above the 97th centile at 5 years. A CT scan shows moderately dilated ventricles. She has no neurological deficit attributable to her hydrocephalus, and her IQ is $\mathbf{1 1 2}$.

The primary treatment was isosorbide in 22 infants. Twelve responded well, including one with severe hydrocephalus, and no surgery was necessary. Ten initially treated with isosorbide needed a shunt later, including 3 with severe hydrocephalus. The 3 in whom ventricular dilatation was particularly pronounced each had a shunt as the primary treatment.

Altogether 17 children with hydrocephalus had no surgical treatment and all survived. In one, shunt treatment was necessary before closure of a large spina bifida lesion to aid healing of the wound and not because of hydrocephalus which was slight.

Five of the 7 with severe hydrocephalus are of normal intelligence. Six have shunts. The seventh had severe hydrocephalus first demonstrated at 6 months. She responded to isosorbide alone and has normal intelligence (WISC full scale 92, verbal 92, performance 89), although a CT scan shows that her ventricles are just as dilated at age 7 years as they were when isosorbide was started, and are grossly asymmetrical. She has no neurological deficit attributable to her hydrocephalus.

Thirteen children had shunts. Ten had between 1 and 4 revisions. During a total of 65 'shunt-years' of observation there were 21 shunt revisions. One child died and another became blind and severely retarded because of shunt blockage (see above).

\section{Intelligence (Table 6)}

Twenty-five children have had formal IQ assessment (Wechsler in 15 children, Stanford-Binet in 10), and 11 have been assessed by school teachers, parents, and us. All the informally assessed are normal and some probably are very intelligent. All 7 without hydrocephalus are of normal intelligence.

Twenty-five of the 29 children with hydrocephalus are of normal or superior intelligence. The 3 with an IQ of 120 or above have no shunts.

Two children without shunts are severely retarded because of microcephaly. Two with severe shunttreated hydrocephalus are retarded because of 
Table 6 Intelligence related to hydrocephalus and its management

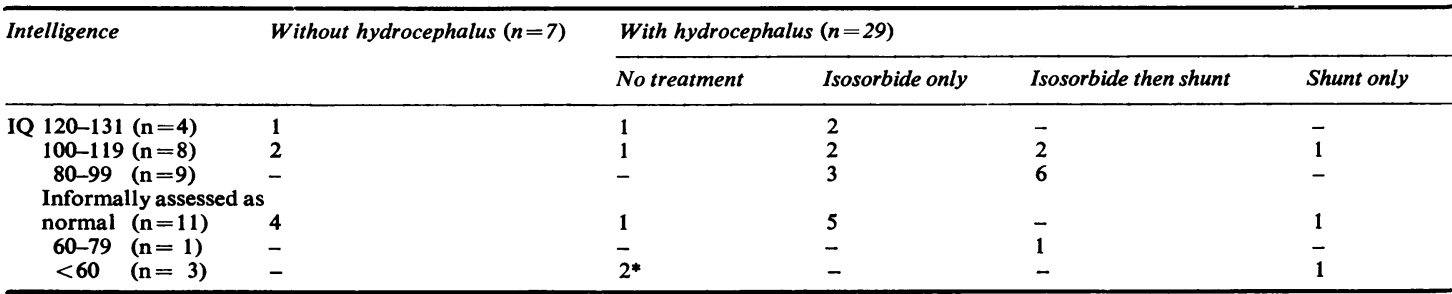

* Both are mentally retarded because of microcephaly.

disastrous shunt complications in one, and no treatment for a long time in the other (see Severely handicapped children).

\section{Locomotion (Table 7)}

Sixteen children walk normally and 6 can walk without aids but with a limp or waddle. Six walk with short calipers or sticks, or both; some use a wheelchair for longer distances.

Five can move with full-length calipers with the aid of elbow sticks. These children use wheelchairs out of doors. Three are wheelchair bound.

\section{Urinary tract (Table 8)}

Thirty children have radiologically normal upper urinary tracts, 20 of whom are continent. Four incontinent children have hydronephrosis or hydroureter, and 2 have vesicoureteric reflux without dilatation of the ureters. None has an ileal conduit. In 14 incontinent children the bladder is emptied by expression or empties spontaneously. One has an indwelling catheter and one is intermittently catheterised.

\section{Schooling}

Twenty-four children already attend school; 13 go to normal and 11 to special schools. Six of the

Table 7 Locomotion in 36 children

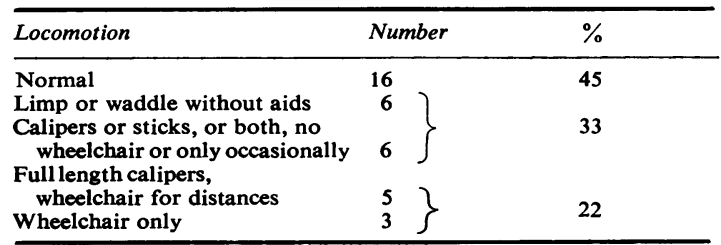

Table 8 Urinary tract in 36 children

\begin{tabular}{lll}
\hline & Number & $\%$ \\
\hline Continent, normal urinary tract & 20 & 55 \\
Incontinent, normal upper renal tract & 10 & 28 \\
Incontinent, abnormal upper renal tract & 2 & 17 \\
Reflux only & 4 & \\
Hydroureter or hydronephrosis & 4 & \\
\hline
\end{tabular}

preschool children are expected to go to normal schools and in 6 a decision has not yet been made.

Untreated infants. Of the 113 patients with myelomeningocele $71(59 \%)$ were not treated, 69 of them had at least one adverse criterion, and 2 were just less severely affected but their parents did not consent to treatment.

Fifty-nine untreated infants had at least two adverse criteria and 11 had four (Table 9).

The two most common adverse criteria, which generally occurred together (Table 10), were thoracolumbar (or thoracolumbosacral) lesion in $82 \%$ and paralysis at least below the 3rd lumbar segmental level in $94 \%$. (The paralysis in most was at a higher segmental level.) Although a grossly enlarged head at birth was one of the adverse criteria, all such infants had other adverse criteria? as well.

The 71 untreated infants died. Twenty-eight per cent survived for one month but only 2 survived beyond age one year (Table 11).

One child lived to age $3 \frac{1}{2}$ years. He was profoundly handicapped and was cared for in his local

Table 9 Number of adverse criteria on admission in 71 untreated patients

\begin{tabular}{ll}
\hline Adverse criteria & No of patients \\
\hline None & $2^{*}$ \\
1 & 10 \\
2 & 21 \\
3 & 27 \\
4 & 11 \\
\hline Parents refused treatment &
\end{tabular}

Table 10 Adverse criteria in 69 untreated infants*

\begin{tabular}{lr}
\hline Gross paralysis below 3rd lumbar spinal segment & 67 \\
Thoracolumbar or thoracolumbo-sacral lesion & 58 \\
Kyphosis or scoliosis & 32 \\
Grossly enlarged head & 9 \\
Cerebral birth injury or gross congenital defects & 12 \\
\hline *Two untreated patients had no adverse criteria but parents refused \\
treatment.
\end{tabular}

Gross paralysis below 3rd lumbar spinal segment Kyphosis or scoliosis

rossly enlarged head

*Two untreated patients had no adverse criteria but parents refused treatment. 
Table 11 Life table of 71 untreated infants with myelomeningocele

\begin{tabular}{lll}
\hline Alive at & Number & $\%$ \\
\hline 1 day & 71 & \\
1 week & 52 & 73 \\
1 month & 22 & 17 \\
3 months & 12 & \\
6 months & 6 & 3 \\
9 months & 3 & \\
1 year & 2 & \\
2 years & 2 & \\
3 years & 1 & \\
4 years & 0 & \\
\hline
\end{tabular}

hospital. He was not referred back when it became apparent that he would live for some time.

Another infant lived to $2 \frac{1}{2}$ years. As she was in good health at age 6 months she was treated with a shunt and back closure, despite her severe handicaps. Two years later she developed pneumococcal meningitis and died in spite of full antibiotic treatment.

The most common causes of death were ventriculitis, hydrocephalus, multiple congenital abnormalities, and respiratory infections. The parents of each untreated infant were seen some 3 months after the death of the infant. They were reassured that they had done nothing wrong either by omission or commission which had resulted in their baby having spina bifida and that neither partner was more 'responsible' than the other, even if there were other cases on one side of the family. They were also given appropriate genetic advice which during most of this period included advice on antenatal diagnosis.

\section{Discussion}

It must be made clear that the results in this paper are those obtained for all the patients referred to one of us (JL) between May 1971, when a policy of selective treatment was started, and December 1976. During the same period paediatricians could alternatively refer patients directly to the Paediatric Surgical Unit (PSU) which at that time did not practise selection.

During this 5-year period, the proportion of infants referred to our medical unit progressively rose (Table 12), while the proportion sent directly to the surgical unit fell, indicating the views of the referring paediatricians on selection. Initially some paediatricians were not aware of the difference in policy and continued the previous practice of referring to the PSU for that reason. Other paediatricians practised selection themselves, and in the earlier years referred the less handicapped infants for surgery direct to the PSU. A few infants with adverse criteria were referred directly to the PSU if the parents insisted on treatment.
Table 12 Surgical and medical admissions of newborn babies with spina bifida cystica to Sheffield Children's Hospital

\begin{tabular}{|c|c|c|c|c|}
\hline \multirow[t]{2}{*}{ Year } & \multicolumn{2}{|c|}{ Surgical $(n=89)$} & \multicolumn{2}{|c|}{ Medical $(n=120)$} \\
\hline & No & $\%$ of total & No & $\%$ of total \\
\hline $\begin{array}{l}1971 \text { (May onwards) } \\
1972 \\
1973 \\
1974 \\
1975 \\
1976\end{array}$ & $\begin{array}{r}31 \\
25 \\
18 \\
7 \\
5 \\
3\end{array}$ & $\begin{array}{l}72 \\
53 \\
50 \\
30 \\
15 \\
11\end{array}$ & $\begin{array}{l}12 \\
22 \\
18 \\
16 \\
28 \\
24\end{array}$ & $\begin{array}{l}28 \\
47 \\
50 \\
70 \\
85 \\
89\end{array}$ \\
\hline
\end{tabular}

Thus the series described does not reflect the total population of spina bifida babies born in the area or admitted to the Sheffield Children's Hospital, and the $59 \%$ of infants with adverse criteria in this series may be different from those found elsewhere.

The survival of $86 \%$ of treated infants in this series is similar to results obtained in other reports of selective treatment (Table 13). The variations are probably due to differences in the application of selection procedures. Lorber ${ }^{2}$ retrospectively showed that in an unselected treated series, $84 \%$ of those without adverse criteria survived.

Not surprisingly, when all infants were treated unselectively in this hospital, the survival rate was considerably lower than for treated infants in selected groups. Spain, ${ }^{18}$ in a community survey for the whole of London, when almost all were unselectively treated, found that only $47 \%$ survived to one year. Ames and Schut ${ }^{19}$ in Philadelphia, on the other hand, reported $78 \%$ survival to between ages 3 and 8 years. They had however, a lower incidence of thoracolumbar lesions in their series than in Sheffield and their intake may well have differed in other ways (Table 14).

The great improvement in the quality of survivors in the present series compared with previous unselected series in the same unit is shown in Table 15. Twenty-four per cent have no handicap, compared with $1 \%$ in unselected groups. Unfortunately

Table 13 Survival of infants selected for treatment in various series

\begin{tabular}{lllll}
\hline & Year & Number & $\begin{array}{l}\text { Survival } \\
(\%)\end{array}$ & Age at reporting \\
\hline $\begin{array}{c}\text { Present series } \\
\text { Guiney } \text { et al.,9 } \\
\text { Dublin }\end{array}$ & $1971-76$ & 42 & 86 & $3-9$ years \\
$\begin{array}{c}\text { Smith and } \\
\text { Smith, } \\
\text { Melbourne }\end{array}$ & $1973-75$ & 77 & 84 & 3 months-3 years \\
$\begin{array}{c}\text { Rickham and } \\
\text { Mawdsley,6 } \\
\text { Liverpool }\end{array}$ & $1961-69$ & 216 & 78 & $3-11$ years \\
$\begin{array}{c}\text { Stark and } \\
\text { Drummond,5 }\end{array}$ & $1965-71$ & 78 & 71 & 3 years \\
\begin{tabular}{c} 
Edinburgh \\
\hline
\end{tabular} & 196500 & 6 years \\
\hline
\end{tabular}


Table 14 Survival of infants treated unselectively in various series

\begin{tabular}{clllll}
\hline & Year & Number & $\begin{array}{l}\text { Survival } \\
(\%)\end{array}$ & $\begin{array}{l}\text { Age at reporting } \\
(\text { years })\end{array}$ \\
\hline $\begin{array}{c}\text { Lorber, } 12 \\
\text { Sheffield }\end{array}$ & a & $1959-63$ & 323 & 41 & $7-12$ \\
& b & $1962-64$ & 200 & 51 & $7-9$ \\
& c & $1967-68$ & 201 & 63 & $2-4$ \\
$\begin{array}{c}\text { Spain, }{ }^{18} \\
\text { London }\end{array}$ & $1967-69$ & 377 & 47 & 1 \\
$\begin{array}{c}\text { Ames and Schut, } \\
\text { Philadelphia }\end{array}$ & $1963-68$ & 148 & 78 & $3-8$ \\
\hline
\end{tabular}

Table 15 Quality of survivors in the selected series, compared with previous unselected series in the same unit $^{1}$

\begin{tabular}{|c|c|c|c|c|c|c|}
\hline \multirow[t]{3}{*}{ Handicap } & \multirow{2}{*}{\multicolumn{2}{|c|}{$\begin{array}{l}\text { Selected } \\
\text { series } \\
1971-76\end{array}$}} & \multicolumn{4}{|c|}{ Unselected series } \\
\hline & & & \multicolumn{2}{|c|}{$1967-68$} & \multicolumn{2}{|c|}{$1959-63$} \\
\hline & $N o$ & $\%$ & No & $\%$ & No & $\%$ \\
\hline $\begin{array}{l}\text { None } \\
\text { Slight or moderate } \\
\text { Severe with IQ } 80+ \\
\text { Severe with IQ } 60-79 \\
\text { Extreme IQ }<60\end{array}$ & $\begin{array}{r}10 \\
16 \\
6 \\
1 \\
3\end{array}$ & $\begin{array}{r}24 \\
38 \\
14 \\
2 \\
7\end{array}$ & $\begin{array}{r}2 \\
11 \\
56 \\
25 \\
20\end{array}$ & $\begin{array}{l}1 \\
5 \cdot 5 \\
28 \\
12 \cdot 5 \\
10\end{array}$ & $\begin{array}{r}4 \\
20 \\
66 \\
28 \\
16\end{array}$ & $\begin{array}{c}1 \\
6 \\
20 \cdot 5 \\
9 \\
5\end{array}$ \\
\hline Total survivors & 36 & 86 & 114 & 57 & 134 & $41 \cdot 5$ \\
\hline Dead & 6 & 14 & 87 & 43 & 189 & $58 \cdot 5$ \\
\hline Total treated & 42 & 100 & 201 & 100 & 323 & 100 \\
\hline
\end{tabular}

$23 \%$ still have severe handicaps but this compares with 34 to $50 \%$ in unselected series. Some of this improvement could be due to greater experience and new technology, and especially to the reduced use of shunts since isosorbide became available. ${ }^{1314}$ However, the main factor is that most of the children who would have been severely handicapped were not treated, and died in infancy.

Earlier publications ${ }^{1-3}$ advocating selection were greeted with enthusiasm by numerous people concerned with the care of severely handicapped children with spina bifida in most parts of the world. When a policy of selection was started by one of us (JL) in 1971, most paediatricians and parents of spina bifida children were in full agreement with the selection procedure. Many units around the world now practise selection, although the criteria vary.

Some have found that when selection was used, surprisingly large numbers of babies who were not operated on in the newborn period survived. However, many infants were treated with shunts in one series, ${ }^{20}$ and in another ${ }^{21}$ there was difficulty in sticking to protocols of selection and management, and active treatment-such as antibiotics-was sometimes used. Shurtleff et $a ._{.}^{22}$ in Seattle, using different selection criteria, found that of 36 infants treated only symptomatically because of adverse criteria, $10 \%$ were surviving at $2 \frac{1}{2}$ years. All the untreated children in the present series died and only 2 out of 71 lived up to one year. In our view if it is decided to withhold closure of the back then it is essential also to withhold other treatment-such as antibiotics, tube feeds, incubator care, shunts, and resuscitation-in the newborn period. The infant should receive normal nursing care, feeding on demand, and analgesia and sedation to relieve discomfort. Many authors have now confirmed that when this is done most severely affected infants die in the first few weeks or months (Table 16).

We believe that parents of infants not selected for treatment should, if possible, be dissuaded from taking their infant home because of the likelihood that they will then receive 'intensive' treatment including antibiotics.

Occasionally, a severely affected infant not chosen for treatment survives, even when all forms of active treatment are withheld. Such a child can still be treated later. This happened with one of our patients whose back was closed and shunt inserted at age 6 months (see Results). The delay in treatment need not worsen the long-term prognosis as such children would have been paraplegic, incontinento and probably would have needed shunt treatmens even if treated in the newborn period. On the contrary, hydrocephalus is often less rapidly progressive if the back is not closed.

There will always be some who object to selection on the grounds that life should be saved at all costs, even if the result is a life of suffering and severe handicaps for the patient and his family. We strongly disagree with this view, as does the predominant opinion of our society and the medical profession. A Department of Health and Social Security memorandum ${ }^{23}$ states ... As physical and intellectual outcome are related to the severity of the initial malformation certain contraindications to active treatment have been suggested' and adds ... 'A decision not to operate implies the existence of a co-ordinated medical and nursing policy which recognises the emotional and ethical problems involved'. A working party under the auspices of

Table 16 Survival of untreated infants with myelomeningocele in various series

\begin{tabular}{lll}
\hline Authors & $\begin{array}{l}\text { No of } \\
\text { patients }\end{array}$ & $\begin{array}{l}\text { Percentage who died } \\
\text { by } 6 \text { months of age }\end{array}$ \\
\hline Present study & 71 & 92 \\
Rickham and Mawdsley6 & 57 & 96 \\
Hide, Williams, and Ellis & 99 & 79 \\
Stark and Drummond5 & 85 & 85 \\
Guiney et al.9 & 50 & 82 \\
\hline
\end{tabular}


the Newcastle Regional Hospital Board ${ }^{24}$ states... 'in the present state of medical knowledge the policy of selection for treatment of spina bifida is in our opinion justified'.

In our opinion a decision to withhold active treatment should be taken with the parents, after expert advice on the expected outcome of treating or not treating the infant.

That the presence of adverse criteria at birth is reliably associated with severe handicap later has been repeatedly demonstrated. 12725 The argument that severe handicap does not necessarily ensue in the presence of adverse criteria is not tenable, even given expert treatment.

However, the absence of adverse criteria does not necessarily ensure a good quality of survival, although it makes it more likely. Seven of 39 infants without adverse criteria at birth became severely handicapped later. The criteria for selection for treatment are sufficiently wide to ensure that any child with a chance of survival with moderate handicap or less will be treated. It is therefore inevitable that some treated infants will become severely handicapped as a result of postnatal events-such as shunt complications, meningitis, ventriculitis, deteriorating neurological status after surgery, or renal problems-or due to problemssuch as microcephaly - which are not predictable in the newborn.

The optimal answer to the problem of myelomeningocele is obviously not selection. The process of selection is extremely painful and distressing for parents, families, paediatricians, nurses and all concerned, both at the decision-making stage and during the life of the infant whether treated or not, and as already stated, appreciable numbers of severely handicapped children still result.

No matter how well they are counselled, it is inevitable that parents of some infants, both treated and untreated, will have doubts about the rightness of their decisions.

Thus the true solution to the problem is prevention. Whether vitamin supplements in early pregnancy ${ }^{26}$ or other means will prove to be effective, remains to be seen. At present antenatal diagnosis and termination of affected pregnancies is the best approach. This has greatly reduced the number of liveborn infants with severe spina bifida in areas like Sheffield, where antenatal screening of all pregnant women has been implemented. In 1979 in Sheffield only one baby was born with myelomeningocele - that is one in 6000 -compared with the national figure of about one in 700 . All pregnant women who have had previous babies with neural tube defects should have estimation of amniotic fluid alpha-fetoprotein ${ }^{27}$ or acetyl-cholinesterase. ${ }^{28}$
It should be an urgent priority to make routine antenatal screening of serum alpha-fetoprotein, ${ }^{29}$ followed when indicated by amniocentesis, nationally available to all pregnant women.

We thank the ward sisters, nursing staff, and junior medical staff for unstinting patient care and understanding of the difficult issues, our surgical colleagues for surgical management, the many paediatricians who referred patients, $\mathrm{Mr}$ A Lonton who did the IQ assessments, and the secretaries for typing the manuscript.

\section{References}

1 Lorber J. Results of treatment of myelomeningocele. An analysis of 524 unselected cases, with special reference to possible selection for treatment. Dev Med Child Neurol 1971; 13: 279-303.

2 Lorber J. Spina bifida cystica. Results of treatment of 270 consecutive cases with criteria for selection for the future. Arch Dis Child 1972; 47: 854-73.

3 Lorber J. Early results of selective treatment of spina bifida cystica. $\mathrm{Br}$ Med J 1973; iv : 201-4.

4 Hide D W, Williams H P, Ellis H L. The outlook for the child with a myelomeningocele for whom early surgery was considered inadvisable. Dev Med Child Neurol 1972; 14: 304-7.

5 Stark G D, Drummond M. Results of selective early operation in myelomeningocele. Arch Dis Child 1973; 48: 676-83.

6 Rickham P P, Mawdsley T. The effect of early operation on the survival of spina bifida cystica. Dev Med Child Neurol 1966; 8: Supplement 11, 20-6.

7 Smith G K, Smith E D. Selection for treatment in spina bifida cystica. Br Med J 1973; iv: 189-97.

8 Colliss V R. The effects of selective treatment of myelomeningocele on a neonatal unit. Dev Med Child Neurol 1972; 14: Supplement 27, 34-7.

9 Guiney E J, Fitzgerald R J, Mehigan D, Purl P, Sundar B. Surgical closure of myelomeningocele: problems and consequences of the introduction of a policy of selection. Ir J Med Sci 1977; 146: 260-2.

10 Freeston B M. An enquiry into the effect of a spina bifida child upon family life. Dev Med Child Neurol 1971; 13: 456-61.

11 Walker J H, Thomas M, Russell I T. Spina bifida-and the parents. Dev Med Child Neurol 1971; 13: 462-76.

12 Lorber J, Schloss A L. The adolescent with myelomeningocele. Dev Med Child Neurol 1973; 15: Supplement 29, 113-4.

13 Lorber J. Isosorbide in treatment of infantile hydrocephalus. Arch Dis Child 1975; 50: 431-6.

14 Hayden P W, Shurtleff D B. The medical management of hydrocephalus. Dev Med Child Neural 1972; 14: Supplement 27, 52-8.

15 Dubowitz V, Lorber J, Zachary R B. Lipoma of the cauda equina. Arch Dis Child 1965; 40: 207-13.

16 Rickwood A M K, Hemalatha V, Zachary R B. Lipoma of the cauda equina (lumbosacral lipoma): a study of $\mathbf{7 4}$ cases operated in childhood. $Z$ Kinderchir 1979; 27: 159-69.

17 Lorber J. Systemic ventriculographic studies in infants born with meningomyelocele and encephalocele. Arch Dis Child 1961 ; 36: 381-9.

18 Spain B. Spina bifida survey. GLC Intelligence Unit Quarterly Bulletin 1970; 12: 5-12. 


\section{Lorber and Salfield}

19 Ames M D, Schut L. Results of treatment of 171 consecutive myelomeningoceles-1963 to 1968 . Pediatrics 1972; 50: 466-70.

20 Robards M F, Thomas G G, Rosenbloom L. Survival of infants with unoperated myeloceles. $\mathrm{Br}$ Med $J$ 1975; iv : $12-3$.

21 Feetham S L, Tweed H, Perrin J S. Practical problems in selection of spina bifida infants for treatment in the USA. $Z$ Kinderchir 1979; 28 : 301-6.

22 Shurtleff D B, Hayden P W, Loeser J D, Kronmal R A. Myelodysplasia: decision for death or disability. $N$ Engl J Med 1974; 291 : 1005-11.

23 The Standing Medical Advisory Committee for the Central Health Services Council, the Secretary of State for Social Services, and the Secretary of State for Wales. Care of the child with spina bifida. London: HMSO, 1973.

24 Newcastle Regional Hospital Board. Ethics of selective treatment of spina bifida. Report by a working party. Lancet 1975 ; i: 85-8.

25 Stein S C, Schut L, Ames M D. Selection for early treatment in myelomeningocele: a retrospective analysis of various selection procedures. Pediatrics 1974; 54: 553-7.
${ }^{26}$ Smithells R W, Sheppard S, Schorah C J, et al. Possible prevention of neural-tube defects by periconceptional vitamin supplementation. Lancet 1980; i: 339-40.

27 Brock D J H, Sutcliffe R G. Alpha-fetoprotein in the antenatal diagnosis of anencephaly and spina bifida. Lancet 1972; ii: 197-9.

28 Smith A D, Wald N J, Cuckle H S, Stirrat G M, Bobrow M, Lagercrantz $\mathbf{H}$. Amniotic-fluid acetylcholinesterase as a possible diagnostic test for neural-tube defects in early pregnancy. Lancet 1979 ; i: 685-8.

29 Wald N J, Brock D J H, Bonnar J. Prenatal diagnosis of spina bifida and anencephaly by maternal serum-alphafetoprotein measurement. Lancet 1974; i: 765-7.

Correspondence to Professor John Lorber, Department of Paediatrics, Children's Hospital, Sheffield S10 2TH.

Received 17 October 1980 